\title{
Carrying weapons and intent to harm among Victorian secondary school students in 1999 and 2009
}

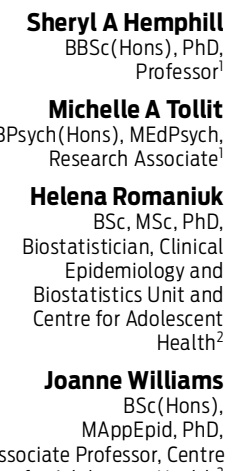

Associate Professor, Centr

for Adolescent Health ${ }^{2}$

John W Toumbourou

MA, PhD

Professor and

Chair in Health Psychology

Lyndal Bond

PhD

Principal Research Officer ${ }^{4}$

George C Patton MD, MB BS, FRANZCP

MD, MB BS, FRANZCP
Professor of Adolescent

Health Research

1 School of Psychology,

Australian Catholic University,

Melbourne, VIC

2 Murdoch Childrens

Research Institute,

Melbourne, VIC

3 Deakin University, Geelong, VIC

4 Centre of Excellence

in Intervention and

Prevention Science Melbourne, VIC.

sheryl.hemphill@

acu.edu.au

MJA 2013; 199: 1-3 doi: 10.5694/mjal2.11645

Online first 02/12/13 outh violence (for example, carrying a weapon or attacking someone with intent to harm) is one of the most important social and public health problems worldwide. ${ }^{1-3}$ The costs of youth violence stem from harm caused to victims, as well as policing and criminal justice responses and community perceptions of reduced safety., ${ }^{3,4}$ Violence was listed in the top three issues concerning young Australians in 2010. ${ }^{5}$ Eight per cent of Victorian students in Years 7 and 9 engaged in violent behaviour in 2002, with higher rates among boys than girls. ${ }^{6}$ In addition, rates of youth violence are higher in disadvantaged communities ${ }^{7}$ and in regional communities with unstable populations and economic structures as well as high unemployment, ${ }^{8}$ and lower among youths from immigrant families. ${ }^{9}$

There have been reports of increases in violent offences perpetrated by youth in Australia ${ }^{10}$ and media reports suggest more youth are violent. ${ }^{11,12}$ National population-based surveys could measure whether rates of selfreported violence among youth have changed over time, but Australia does not have such surveys. In this article, we analyse data from Victorian surveys of secondary school students in 1999 and 2009 to examine whether rates of carrying a weapon and attacking someone with intent to harm have increased, after adjusting for sample demographic characteristics.

\section{Methods}

Data for this study were drawn from two Victorian cross-sectional surveys; the 1999 Adolescent Health and Wellbeing Survey ${ }^{13}$ and the 2009 Victorian Adolescent Health and Wellbeing Survey (HOWRU). ${ }^{14}$ Both surveys

Abstract

Objective: To examine comparable survey data across 10 years to assess whether rates of self-reported weapon carrying and intent to harm others have increased as suggested in reported trends in violent offences.

Design, setting and participants: Population-based surveys administered to Victorian secondary school students in 1999 (8984 students) and 2009 (10 273 students) attending government, Catholic and independent schools.

Main outcome measures: Student self-reports of carrying a weapon and attacking someone with the intent to harm in the past 12 months.

Results: In both surveys, about $15.0 \%$ of students reported carrying a weapon and about $7.0 \%$ reported attacking someone with intent to harm in the past 12 months, with higher rates among boys than girls. There was no change over time in the rates of students carrying weapons or attacking someone with the intent to harm, after controlling for demographic variables.

Conclusions: In contrast to media portrayals and reported trends in violent offences, rates of students carrying weapons and attacking others with intent to harm have not changed between 1999 and 2009. These findings underline the importance of having national population-based data to regularly monitor the rates of these and related behaviours among young Australians.

used a modified version of the Communities That Care Youth Survey ${ }^{15,16}$ to measure behavioural and mental health outcomes, as well as risk and protective factors.

Both surveys used a two-stage cluster sampling approach. The first stage consisted of a stratified random sample of government (public) and nongovernment (Catholic and independent) schools from each of 36 areas across Victoria - the 31 metropolitan government areas and the five state government regions outside the metropolitan area. Schools were selected randomly with a probability proportional to the number of Year 7, 9 and 11 students in the school. In the second stage, a random sample was taken of one class at each year level.

Data collection covered the first three school terms (February to September) in 1999 and the second and third terms (April to November) in 2009. Responses to questionnaires were anonymous. Students completed the questionnaire in class, taking about 40 minutes in 1999 for a pen-and-paper survey and about 60 minutes in 2009 to complete a longer online survey (although computers were not available for $19 \%$ of surveys, so paper versions were used). Students were supervised by trained research staff while they completed the survey. In 1999, copies of the questionnaire with a prepaid return envelope were left at the school to be returned to researchers by students who were absent on the day of the survey. For 2009, there was no follow-up to collect surveys from absent students.

\section{Measures}

Carrying a weapon was measured by asking students whether in the past 12 months they had carried a weapon. Attacking someone with intent to harm was measured by asking students whether in the past 12 months they had attacked someone with the idea of seriously hurting them. In the 1999 survey, participants responded to both questions on an 8-point scale ranging from "No" to "Yes, more than 40 
1 Description of the Victorian secondary school samples in 1999 and 2009

\begin{tabular}{|c|c|c|}
\hline Descriptor & 1999 Survey & 2009 Survey \\
\hline \multicolumn{3}{|l|}{ School sample } \\
\hline \multicolumn{3}{|l|}{ Number of government areas } \\
\hline Metropolitan & 31 & 31 \\
\hline Regional & 5 & 5 \\
\hline \multicolumn{3}{|l|}{ Number of schools } \\
\hline In sampling frame* & 535 & 740 \\
\hline Approached & 309 & 357 \\
\hline Recruited & 194 & 189 \\
\hline \multicolumn{3}{|l|}{ Type of school } \\
\hline Government & $126(65.0 \%)$ & $112(59.3 \%)$ \\
\hline Catholic & $41(21.1 \%)$ & $40(21.2 \%)$ \\
\hline Independent & $27(13.9 \%)$ & $37(19.6 \%)$ \\
\hline \multicolumn{3}{|l|}{ Student sample } \\
\hline Total number in analysed sample & 7998 & 9364 \\
\hline Mean age in years (SE) & $14.1(0.02)$ & $14.4(0.02)$ \\
\hline Male & $3622(45.3 \%)$ & $4492(48.0 \%)$ \\
\hline English spoken at home & $6500(81.3 \%)$ & $6942(74.1 \%)$ \\
\hline School located in metropolitan area & $5811(72.7 \%)$ & $7878(84.1 \%)$ \\
\hline \multicolumn{3}{|l|}{ Neighbourhood disadvantage } \\
\hline Most disadvantaged & $2007(25.1 \%)$ & $2378(25.4 \%)$ \\
\hline Disadvantaged & $2004(25.1 \%)$ & $2466(26.3 \%)$ \\
\hline Advantaged & $1982(24.8 \%)$ & $2164(23.1 \%)$ \\
\hline Most advantaged & $2005(25.1 \%)$ & $2356(25.2 \%)$ \\
\hline
\end{tabular}

times". In the 2009 survey, items were rated on a 5 -point scale ranging from "Never" to "10 or more times". For both surveys, responses to these items were recoded and dichotomised to 0 ("No/Never") or 1 ("At least once").

Demographic measures controlled in the analyses included age, sex, language spoken at home, and geographic location of school. Student residential socioeconomic disadvantage was measured using four quartiles: $(0-25$ th quartile [most disadvantaged], 26th-50th quartile [disadvantaged], 51st-75th quartile [advantaged] and 76th-100th quartile [most disadvantaged]), on the index of relative socioeconomic disadvan- tage from the Australian Bureau of Statistics' Socio-Economic Indices for Areas (SEIFA) for 1996 and 2006. ${ }^{17,18}$

\section{Statistical analysis}

Prevalence rates with 95\% CIs were estimated for the outcomes of interest in each survey. In unadjusted analyses, the relationship between year of survey and the outcomes was analysed by logistic generalised estimating equations (GEE) to take account of the clustering of students in schools. These analyses were then repeated, controlling for all demographic measures. A complete case analysis was performed with Stata, version 11 (StataCorp), that included only students who responded to all the variables analysed here.

\section{Ethics approval}

Ethics approval for both surveys was obtained from the Royal Children's Hospital Human Research Ethics Committee and relevant education authorities. For the 1999 survey, active informed consent was required from parents for students to participate. In the 2009 survey, passive informed consent from parents was required in most schools, but active informed consent from parents was required at some Catholic schools. For both surveys, informed assent was sought from students on the day of the survey.

\section{Results}

The student participation rate was $70 \%$ (8984 students) in the 1999 survey and $76 \%$ (10 273 students) in the 2009 survey. There were complete case data for $92 \%$ of students in the 1999 survey (7998) and 91\% of students in the 2009 survey (9364). Box 1 describes the school and student samples for each survey.

The prevalence rate for carrying a weapon was about $15.0 \%$ in both the 1999 and 2009 surveys and the prevalence rate for attacking someone with intent to harm was about $7.0 \%$ in both surveys. Rates for both outcomes did not differ over time. More boys than girls engaged in these behaviours (Box 2).

\section{Discussion}

We found no change over time in the self-reported rates of student violent behaviour based on two indicators, carrying weapons or attacking someone with intent to harm, even after

2 Rates of carrying a weapon and attacking someone with intent to harm in 1999 and 2009

\begin{tabular}{|c|c|c|c|c|c|c|c|c|}
\hline & \multicolumn{4}{|c|}{ Carrying a weapon } & \multicolumn{4}{|c|}{ Attacking someone with intent to harm } \\
\hline & \multicolumn{2}{|r|}{1999} & \multicolumn{2}{|r|}{2009} & \multicolumn{2}{|r|}{1999} & \multicolumn{2}{|r|}{2009} \\
\hline & No. & $\%(95 \% \mathrm{Cl})$ & No. & $\%(95 \% \mathrm{Cl})$ & No. & $\%(95 \% \mathrm{Cl})$ & No. & $\%(95 \% \mathrm{Cl})$ \\
\hline Population & 7998 & & 9364 & & 7998 & & 9364 & \\
\hline Overall sample* & 1208 & 15.1\% (14.3\%-15.9\%) & 1396 & 14.9\% (14.2\%-15.6\%) & 598 & $7.5 \%(6.9 \%-8.1 \%)$ & 685 & $7.3 \%(6.8 \%-7.8 \%)$ \\
\hline Girls & 334 & $7.6 \%(6.9 \%-8.4 \%)$ & 346 & $7.1 \%(6.4 \%-7.8 \%)$ & 192 & $4.4 \%(3.8 \%-5.0 \%)$ & 215 & $4.4 \%(3.8 \%-5.0 \%)$ \\
\hline Boys & 874 & $24.1 \%(22.7 \%-25.5 \%)$ & 1050 & $23.4 \%(22.1 \%-24.6 \%)$ & 406 & $11.2 \%(10.2 \%-12.2 \%)$ & 470 & $10.5 \%(9.9 \%-11.4 \%)$ \\
\hline
\end{tabular}

* For the overall sample, we found no difference in rates between 1999 and 2009 surveys whether findings were or were not adjusted for demographic characteristics. This was the case for both carrying a weapon (unadjusted odds ratio [OR], 1.0; 95\% $\mathrm{Cl}, 0.9-1.1$ and adjusted OR, 0.9; 95\% $\mathrm{Cl}, 0.8-1.1$ ) and attacking someone with intent to harm (unadjusted OR, 1.0, 95\% Cl, 0.8-1.1 and adjusted OR, 0.9; 95\% Cl, 0.8-1.0). 
controlling for demographic changes. Our findings suggest that changes in policing and court policies rather than in youth behaviour may explain increases in violence offences. ${ }^{19}$ Consistent with previous research, ${ }^{7}$ more boys than girls carried weapons or attacked another with intent to harm.

A strength of our study is that the methods used in the 1999 and 2009 surveys were virtually identical, enabling comparison of rates of behaviour across a 10-year period. However, response rates in the two surveys differed, with a lower response rate in 1999, most likely most likely because that survey required active parental consent. The survey measures, which originated in the United States, have been used in other high-income countries, and had been extensively tested before their use with Victorian students. Although the survey relies on youth self-report, this is considered a reliable data source for behaviours not always visible to adults, such as violence, and the reliability of reporting is unlikely to have changed over the decade. ${ }^{20,21}$

Violence in adolescence remains an important social and health issue. Yet our study challenges trends in offence data and recent media reports of increasing youth violence by finding no shifts in two self-report indices between 1999 and 2009. Our findings illustrate the need for sound selfreport data for planning balanced policy responses and to challenge some negative media portrayals that can create erroneous and damaging stereotypes of young people. ${ }^{22}$

Acknowledgements: Completion of the Adolescent Health and Wellbeing Survey in 1999 was made possible by funding from the Victorian Department of Human Services. In 2009, the Victorian Adolescent Health and Wellbeing Survey (HOWRU) was funded by the Victorian
Department of Education and Early Childhood Development. The analyses of this data were supported by funding from the Centre for Adolescent Health's Adolescent Forensic Health Service, Royal Children's Hospital. We express our appreciation and thanks to project staff and participants for their valuable contribution to the two projects described in this article.

Competing interests: No relevant disclosures.

Received 8 Nov 2012, accepted 8 Jul 2013

1 Herrenkohl TI, Maguin E, Hill KG, et al. Developmental risk factors for youth violence. J Adolesc Health 2000; 26: 176-186.

2 Rutherford A, Zwi A, Grove NJ, Butchart A Violence: a priority for public health? (part 2) JEpidemiol Community Health 2007; 61: 764-770.

3 World Health Organization. World report on violence and health: summary. Geneva: WHO 2002. http://www.who.int/entity/violence injury_prevention/violence/world_report/en/ summary_en.pdf (accessed Jul 2013).

4 Waters H, Hyder A, Rojkotia Y, et al. The economic dimensions of interpersonal violence. Geneva: Department of Injuries and Violence Prevention, World Health Organization, 2004. http:// whqlibdoc.who.int/publications/2004/ 9241591609.pdf (accessed Jul 2013).

5 Mission Australia. National survey of young Australians 2010: key and emerging issues. Sydney: Mission Australia, 2010. https://www. missionaustralia.com.au/research-page/youngpeople-page?view=docman (accessed Jul 2013)

6 Hemphill SA, Smith R, Toumbourou JW, et al. Modifiable determinants of youth violence in Australia and the United States: a longitudinal study. Aust N Z J Criminol 2009; 42: 289-309.

7 Toumbourou JW, Hemphill SA, Tressider J, et al. Mental health promotion and socio-economic disadvantage: lessons from substance abuse, violence and crime prevention and child health. Health Promot J Austr 2007; 18: 184-190.

8 Carcach C. Regional crime and development. Trends and Issues in Crime and Criminal Justice 2000; (160): 1-6. http://www.aic.gov.au/ documents/F/8/2/\%7bF82488C4-AFE6-4163B3F5-F1066D7733B7\%7dti160.pdf (accessed Jul 2013).

9 Collins J. Ethnic minorities and crime in Australia: moral panic or meaningful policy responses. Paper presented at a public seminar organised by the Office of Multicultural Interest, WA:2005 Nov 8; Perth, Australia. http://www.omi.wa.gov.au/ resources/clearinghouse/Ethnic_Minorities_and Crime.pdf (accessed Jun 2013).

10 Bricknell S. Trends in violent crime. Trends and Issues in Crime and Criminal Justice 2008; (359): 1-6. http://www.aic.gov.au/media_library/ publications/tandi_pdf/tandi359.pdf (accessed Jul 2013)

11 Tame A. Sad increase of youth violence. Herald Sun (Melbourne) 2007; 9 Sep. http://www. heraldsun.com.au/news/victoria/sad-increase- of-youth-violence/story-e6frf7kx-111114373899 (accessed Aug 2012).

12 Estrada F. Juvenile violence as a social problem. Trends, media attention and societal response. Br J Criminol 2001; 41: 639-655. doi: 10.1093/bjc/ 41.4.639.

13 Bond L, Thomas L, Toumbourou J, et al. Improving the lives of young Victorians in our community: a survey of risk and protective factors. Melbourne: Centre for Adolescent Health, 2000. http://ercweb.rch.org.au/cah/Improving the_lives_of_young_Victorians.pdf (accessed Jul 2013).

14 Department of Education and Early Childhood Development. Adolescent community profiles [website with links to profiles]. http://www. education.vic.gov.au/about/research/pages/ reportdataadolescent.aspx (accessed Oct 2013).

15 Arthur MW, Hawkins JD, Pollard JA, et al. Measuring risk and protective factors for substance use, delinquency, and other adolescent problem behaviors. The Communities That Care Youth Survey. Eval Rev 2002; 26 : 575-601.

16 Glaser RR, Van Horn L, Arthur MW, et al. Measurement properties of the Communities That Care Youth Survey across demographic groups. J Quant Criminol 2005; 21: 73-102. doi: 10.1007/s10940-004-1788-1.

17 Australian Bureau of Statistics. Information paper: Census of Population and Housing Socio-Economic Indexes for Areas, Australia, 1996. Canberra: ABS, 1998. (ABS Cat. No. 2039.0.) http://www.abs.gov.au/AUSSTATS/ abs@.nsf/DetailsPage/2039.01996 (accessed Jul 2013).

18 Australian Bureau of Statistics. Socio-Economic Indexes for Areas (SEIFA) -Technical Paper, 2006. Canberra: ABS, 2008. (ABS Cat. No. 2039.0.55.001.) http://www.abs.gov.au/ ausstats/abs@.nsf/mf/2039.0.55.001 (accessed Jul 2013)

19 Cunneen C, White R. Juvenile justice: youth and crime in Australia. 4th ed. Melbourne: Oxford University Press, 2011.

20 Huizinga D, Elliott DS. Reassessing the reliability and validity of self-report delinquency measures. J Quant Criminol 1986; 2: 293-327. doi: 10.1007/ BF01064258.

21 Jolliffe D, Farrington DP, Hawkins JD, et al. Predictive, concurrent, prospective and retrospective validity of self-reported delinquency. Crim Behav Ment Health 2003; 13: 179-197.

22 Wyn J. Youth in the media: adult stereotypes of young people. In: Williams A, Thurlow C, editors. Talking adolescence: perspectives on communication in the teenage years. New York, NY: Peter Lang, 2005: 23-34.

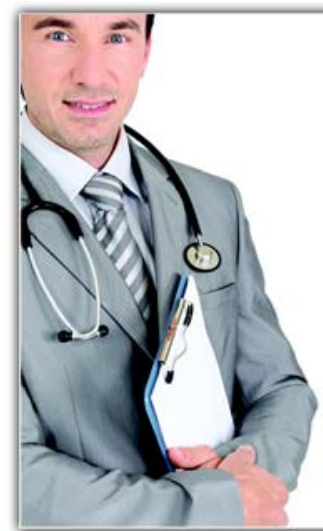

Calling all general practice researchers and opinion leaders

We want to host your best research, and to publish relevant comment on issues affecting general practice as they arise. Our call comes with a promise to prioritise excellent research, and to smooth the path to publication.

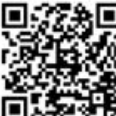

See our instructions to authors for submission guidelines. 